\title{
ORIGINAL
}

\section{Pre-operative Weight Loss Program for Obese Patients Undergoing Laparoscopic Gastrectomy}

\author{
Hideya Kashihara, Mitsuo Shimada, Kozo Yoshikawa, Jun Higashijima, Takuya Tokunaga, Masaaki Nishi, \\ Chie Takasu, and Toshiaki Yoshimoto \\ Department of Surgery, Tokushima University, Tokushima, Japan
}

\begin{abstract}
Background: The aim of this study was to investigate the influence of obesity and the usefulness of a pre-operative weight loss program (PWLP) for obese patients undergoing laparoscopic gastrectomy (LG) for gastric cancer (GC). Materials and Methods : Study1 : 219 patients who underwent laparoscopic distal gastrectomy (LDG) for GC were divided into 2 groups : body mass index (BMI) $\geqq 28$ and BMI $<28 \mathrm{~kg} / \mathrm{m}^{2}$. The influence of BMI in LG surgery was investigated. Study2 : The BMI $\geqq 28 \mathrm{~kg} / \mathrm{m}^{2}$ patients with a planned LG $(\mathrm{n}=8)$ undertook a PWLP including calorie restriction and exercise. The effects of this program were evaluated. Results : Study1 : The BMI $\geqq 28 \mathrm{~kg} / \mathrm{m}^{2}$ group showed significantly longer operation times, more blood loss and a higher frequency of post-operative complications than that of the BMI $<28 \mathrm{~kg} / \mathrm{m}^{2}$ group. Study 2 : The patients achieved a weight

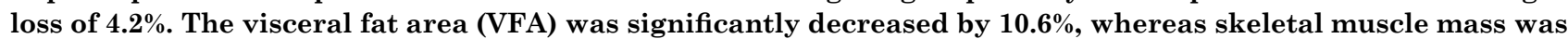
unaffected. The PWLP group showed shorter operation times, less blood loss and a lower frequency of post-operative complications compared with that of the BMI $\geqq 28 \mathrm{~kg} / \mathrm{m}^{2}$ group. Conclusion : Obesity is an important risk factor and a pre-operative weight loss program is useful for obese patients undergoing a LG. J. Med. Invest. 68: 165-169, February, 2021
\end{abstract}

Keywords : pre-operative weight loss program (PWLP), laparoscopic gastrectomy (LG), gastric cancer (GC)

\section{INTRODUCTION}

Since laparoscopic gastrectomy (LG) surgery for gastric cancer was firstly reported in 1994, the number of patients who have undergone a LG has been increasing (1). A LG is reported to have some major advantages compared with conventional open gastrectomy : less blood loss ; less post-operative pain ; less respiratory dysfunction; and shorter hospital stays $(2,3)$.

However, obesity is one of the important risk factors for the manifestation of technical difficulties and post-operative complications. Kunisaki, et al. reported that a high body mass index (BMI) and a high visceral fat area (VFA) could predict technical difficulties and post-operative complications for LG surgery (4). Regarding post-operative pancreatic fistula (POPF), male patients with a high BMI were identified in uni-variate and multi-variate analyses as risk factors associated with POPF after a laparoscopic distal gastrectomy (LDG) (5). In this report, the POPF group had a high incidence of longer operation times, post-operative complications and longer post-operative hospital stays.

The aim of this study was to investigate the influence of obesity in LG surgery retrospectively and the usefulness of a pre-operative weight loss program (PWLP) for obese patients undergoing a LG for gastric cancer (GC) prospectively.

\section{MATERIALS AND METHODS}

Studyl : The influence of BMI in LG surgery

From January 2002 through December 2016, 219 patients (167 male and 52 female; age range from 38- 85 years (mean age 69.0 years)) were referred to the Tokushima University Hospital for the treatment of GC. These 219 patients underwent LDGs. Written informed consent was provided by each patient before surgery. LDGs with D1 or D1+ lymph node dissection were performed for clinical stage IA cancers and LDGs with D2 dissection were performed for stage IB, II, III cancers. Staging for all the cancers was based on the Japanese Classification of Gastric Carcinoma (JCGC) (6).

In this study, there were two (2) groups : $\mathrm{BMI} \geqq 28$ (BMI $\geqq 2$ $\left.8 \mathrm{~kg} / \mathrm{m}^{2} ; \mathrm{n}=14\right) ;$ and $<28 \mathrm{~kg} / \mathrm{m}^{2}\left(\mathrm{BMI}<28 \mathrm{~kg} / \mathrm{m}^{2} ; \mathrm{n}=205\right)$. The patients' backgrounds in both groups are shown in Table 1.

\section{Study2 : A PWLP for LG surgery}

The protocol for this research project was approved by a suitably constituted Ethics Committee of the Tokushima University Hospital.

The indication for a PWLP at the Tokushima University Hospital consisted of a BMI $\geqq 28 \mathrm{~kg} / \mathrm{m}^{2}$, early GC (Tumor depth ; cM or (SM) and a planned LG. Written informed consent was provided by each patient before surgery.

The exclusion criteria were conditions associated with poor

Received for publication December 7, 2020 ; accepted January 21, 2021.

Address correspondence and reprint requests to Hideya Kashihara, M.D., PhD., Department of Surgery, Tokushima University, 3-18-15 Kuramoto-cho, Tokushima, 770-8503, Japan and Fax : +81-88-631-9698. pre-operative weight loss program (PWLP) ; laparoscopic gastrectomy (LG) ; gastric cancer (GC) ; laparoscopic distal gastrectomy (LDG) ; body mass index (BMI); body weight (BW) ; visceral fat area (VFA) ; post-operative pancreatic fistula (POPF) ; activities of daily living (ADL) ; aspartic aminotransferase (AST) ; alanine aminotransferase (ALT) ; Japanese Classification of Gastric Carcinoma (JCGC) ; skin-to-celiac artery distance (SCD) ; C reactive protein (CRP) ; living donor liver transplantation (LDLT) ; hepatocellular carcinoma (HCC). 
Table 1. Patients' characteristics in the BMI $\geqq 28$ and $<28$ groups.

\begin{tabular}{lccc}
\hline Factors & $\begin{array}{c}\mathrm{BMI} \geqq 28 \\
(\mathrm{n}=14)\end{array}$ & $\begin{array}{c}\mathrm{BMI}<28 \\
(\mathrm{n}=205)\end{array}$ & p value \\
\hline Age (y.o.) & $\begin{array}{c}65.4 \pm 6.9 \\
(51-83)\end{array}$ & $\begin{array}{c}69.2 \pm 11.3 \\
(38-85)\end{array}$ & 0.71 \\
Gender $:$ male/female & $10 / 4$ & $157 / 48$ & 0.65 \\
& $29.2 \pm 0.8$ & $22.5 \pm 2.8$ & $<0.01$ \\
BMI $\left(\mathrm{kg} / \mathrm{m}^{2}\right)$ & $(28.1-30.7)$ & $(16.6-27.9)$ & \\
Depth of invasion: & $8 / 4 / 2 / 0$ & $139 / 36 / 26 / 4$ & 0.90 \\
M, SM/MP/SS/SE & $10 / 4$ & $155 / 50$ & 0.75 \\
Dissection : D1, 1+/2 & $12 / 2$ & $177 / 28$ & 0.94 \\
fStage : I/II, III & &
\end{tabular}

The Mann-Whitney U test was used for the statistical analysis of the continuous variables and the $\chi^{2}$ test was used for categorical variables. $\mathrm{P}<0.05$ was interpreted as significant. The values for each continuous variable are expressed as a mean \pm the standard deviation (SD).

compliance (psychiatric illness).

The PWLP contained calorie restriction (total 1,200kcalories) and exercise (matched age and activities of daily living (ADL)) for 10 - 30days. The exercise in the PWLP had standing exercises, leg presses, calf raises, ergometer and self-training in the Department of Rehabilitation.

The primary endpoint was a minimization or exclusion of post-operative complications. The secondary endpoints were : weight loss ; VFA ; body fat mass ; skeletal muscle ; nutritional parameters ; operative time ; blood loss ; and length of hospital stay. The data regarding VFA, body fat mass and skeletal muscle were obtained by the InBody $770 \AA$.

Table 2 showed the characteristics of the patients' in the PWLP. The BMI $\geqq 28 \mathrm{~kg} / \mathrm{m}^{2}$ patients with a planned LG $(\mathrm{n}=8$, body weight (BW) $73.1 \mathrm{~kg}$, BMI $30.1 \mathrm{~kg} / \mathrm{m}^{2}$ ) underwent the PWLP. Regarding co-morbidity, there were three (3) patients with diabetes, one (1) with renal failure, five (5) with cardiovascular diseases and one (1) using steroid. The mean duration of the PWLP was 26.3 (range 19 - 40) days.

General clinical and clinic-pathological data from each eligible patient were retrieved from medical reports. All data was reviewed retrospectively and the Clavien-Dindo Classification was used to compare the short-term complication rate during the inpatient hospital stay.

Table 2. Patients' characteristics in the PWLP group.

\begin{tabular}{lc}
\hline Factors & $\mathrm{n}=8$ \\
\hline Age (y.o.) & $69.8 \pm 7.5(58-81)$ \\
Gender : male/female & $6 / 2$ \\
BMI (kg/m2) & $30.1 \pm 7.9(28.0-34.8)$ \\
Body weight (kg) & $73.1 \pm 6.3(58.5-81.7)$ \\
Comorbidity (+/-) & $8 / 0$ \\
Duration of PWLP (days) & $4 / 3 / 1$ \\
Operation (LDG/LTG/LPPG) & $7 / 1$ \\
fStage (I/II) & $26.3 \pm 6.6-40)$ \\
\hline
\end{tabular}

The Mann-Whitney U test was used for the statistical analysis of the continuous variables and the $\chi^{2}$ test was used for categorical variables. $\mathrm{P}<0.05$ was interpreted as significant. The values for each continuous variable are expressed as a mean \pm the standard deviation (SD).

\section{Statistical analysis}

The unpaired/paired Student's t-test or the Mann-Whitney $\mathrm{U}$ test were used for the statistical analysis of the continuous variables and the $\chi^{2}$ test was used for the categorical variables. For all three (3) tests, $p<0.05$ was interpreted as significant. The values for each continuous variable are expressed as a mean \pm the standard deviation (SD).

\section{RESULTS \\ Studyl : The influence of the BMI in LG surgery}

Figures $1 \mathrm{a}$ and $1 \mathrm{~b}$ show the operation times and intra-operative blood loss in the BMI $\geqq 28$ and $<28$ groups. The BMI $\geqq 28$ group had significantly longer operation times and more blood loss than the BMI $<28$ group. Furthermore, the BMI $\geqq 28$ group had a high incidence of post-operative complications (Clavien-Dindo > gradeII) including pancreatic fistula (Figure 1c). Regarding post-operative hospital stay, there was no significant difference between the two (2) groups (Figure 1d).

\section{Study2 : A PWLP for LG surgery}

In Study2, the effects of a PWLP on the BMI $\geqq 28$ patients for planned LG surgery were evaluated.

The patients achieved a weight loss of $4.2 \%(-3.1 \mathrm{~kg})$ (Figure $2 \mathrm{a}, \mathrm{b})$. VFA and body fat mass were significantly decreased (VFA $10.6 \%$; body fat mass $5.8 \%$ ) (Figure $2 \mathrm{c}, \mathrm{d}$ ), whereas skeletal muscle mass was unaffected (Figure 2e).

Total cholesterol and triglyceride counts were decreased (Figure $3 \mathrm{a}, \mathrm{b})$. However, albumin showed no significant difference (Figure 3c). Aspartic aminotransferase (AST) and alamine aminotransferase (ALT) on post-PWLP examination were significantly lower than that on pre-PWLP examination indicating that a PWLP might contribute to the improvement of fatty liver (Figure 3d, e).

The PWLP group showed shorter operation times, less blood loss (Figure 4a, b) and lower frequency of post-operative complications compared with that in the $\mathrm{BMI} \geqq 28 \mathrm{~kg} / \mathrm{m}^{2}$ group (Figure 4c). Furthermore, this program was correlated with shorter post-operative hospital stays compared with that in the $\mathrm{BMI} \geqq 28 \mathrm{~kg} / \mathrm{m}^{2}$ group (Figure $4 \mathrm{~d}$ ).

\section{DISCUSSION}

This study was designed to investigate the influence of obesity on LG surgery and the usefulness of a PWLP for obese patients undergoing LG surgery for GC. The BMI $\geqq 28 \mathrm{~kg} / \mathrm{m}^{2}$ group showed significantly longer operation times, more blood loss and a higher frequency of post-operative complications than that in the BMI $<28 \mathrm{~kg} / \mathrm{m}^{2}$ group. The PWLP group achieved a decrease of BW and visceral fat mass. This group showed shorter operation times, less blood loss and lower frequency of post-operative complications compared with that in the $\mathrm{BMI} \geqq 28 \mathrm{~kg} / \mathrm{m}^{2}$ group.

In the authors' previous report the patients with a high VFA $\left(\geqq 100 \mathrm{~cm}^{2}\right)$ had an increase in the incidence of post-operative complications and intra-operative blood loss while the number of dissected lymph nodes decreased. On the one hand, the VFA was reported to be superior to the BMI as a predictive factor for risk with LG surgery for GC (7). On the other hand, Goto, et al. reported that the 'skin-to-celiac artery distance (SCD)' was a simple predictive index for longer operation times during LDG surgery (8). Several reports showed the correlation between the obesity-related parameters and the risk factors in LG surgery such as operation time, blood loss and post-operative complications 


\section{a. Operation time}

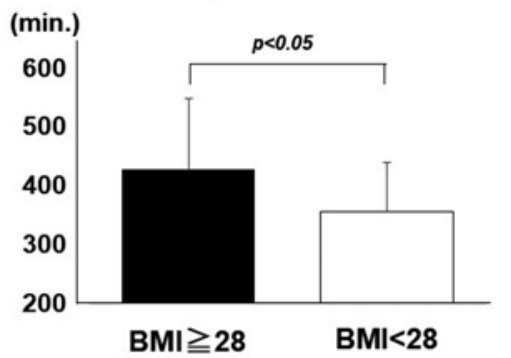

c. Postoperative complications (Clavien-Dindo > II)

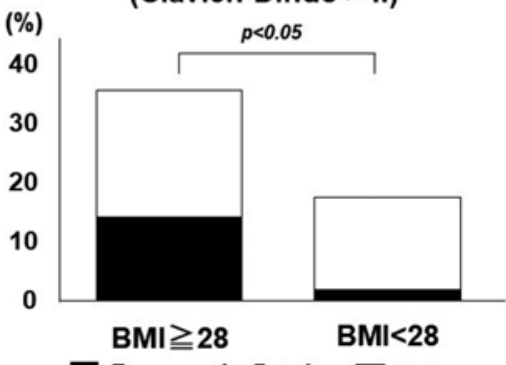

b. Blood loss

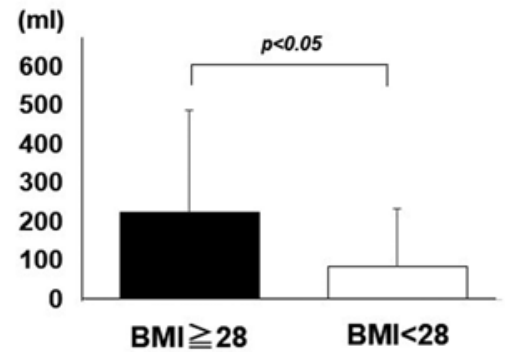

\section{d. Postoperative hospital stay}

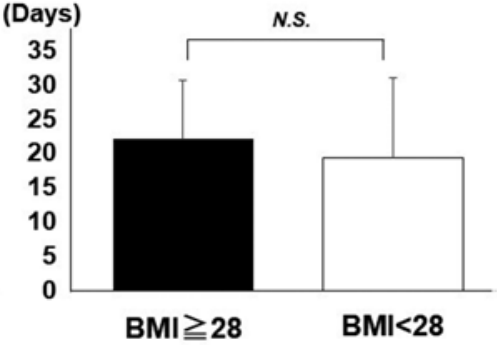

Figures 1a - 1d. Comparisons of operation time (1a), blood loss (1b), post-operative complications (1c) and post-operative hospital stay (1d) in the BMI $\geqq 28$ and $<28$ groups.

The unpaired Student's t-test was used for the statistical analysis of the continuous variables. $\mathrm{P}<0.05$ was interpreted as significant. The values for each continuous variable are expressed as a mean \pm the standard deviation (SD).

\section{a. Body weight}

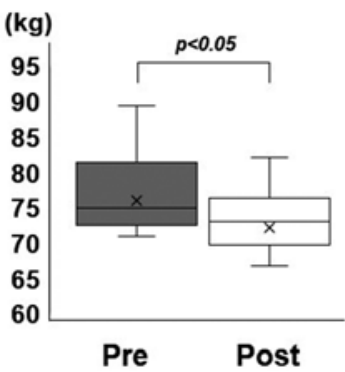

d. Body fat mass

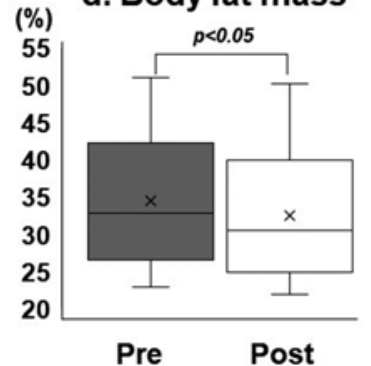

b. BMI

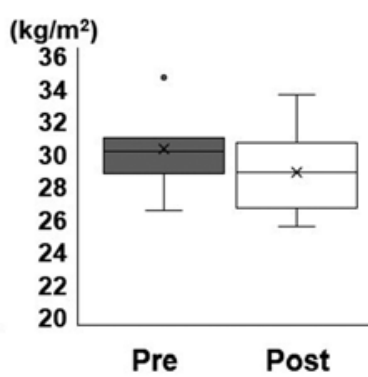

e. Skeletal muscle

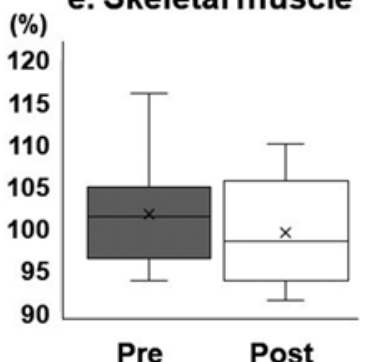

c. Visceral fat area

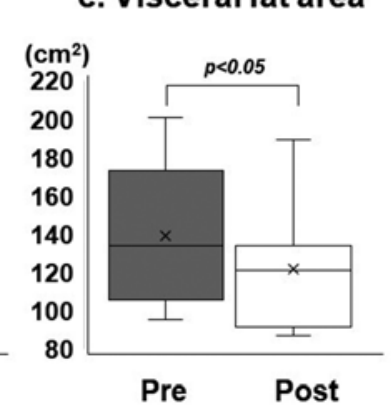

Figures $2 \mathrm{a}-2 \mathrm{e} . \quad$ Comparisons of BW (2a), BMI (2b), VFA (2c), body fat mass (2d) and skeletal muscle (2e) pre- and post-PWLP.

The paired Student's t-test was used for the statistical analysis of the continuous variables. $\mathrm{P}<0.05$ was interpreted as significant. The values for each continuous variable are expressed as a mean \pm the standard deviation (SD). 
a. Total cholesterol

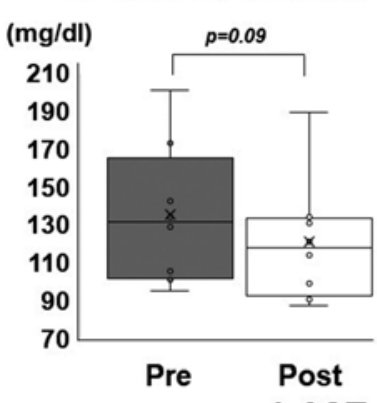

d. AST

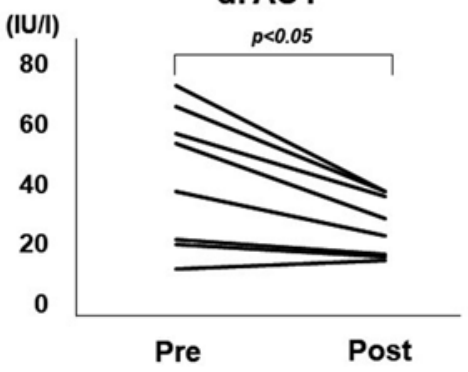

b. Triglyceride

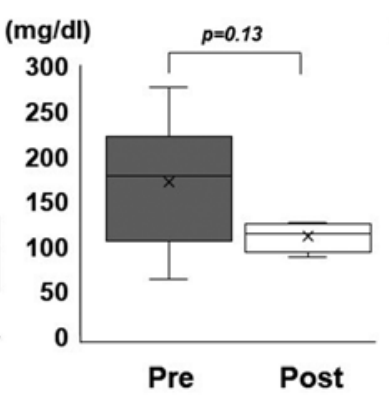

Pre c. Albumin

(g/dl)

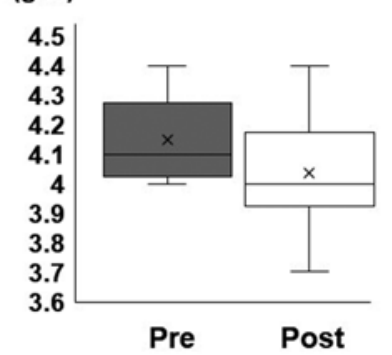

e. ALT

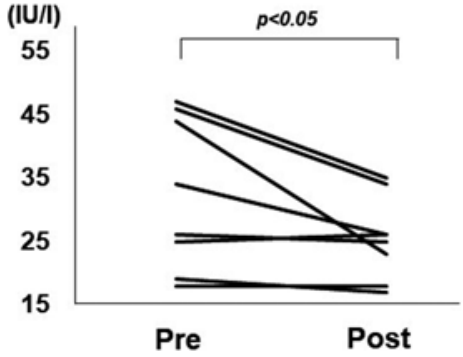

Figures 3a - 3e. Comparisons of total cholesterol (3a), triglyceride (3b), albumin (3c), AST (3d) and ALT (3e) pre- and post-PWLP.

The paired Student's t-test was used for the statistical analysis of the continuous variables. $\mathrm{P}<0.05$ was interpreted as significant. The values for each continuous variable are expressed as a mean \pm the standard deviation (SD).

a. Operation time

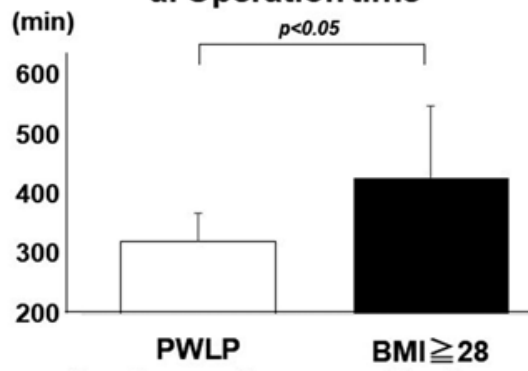

c. Postoperative complications

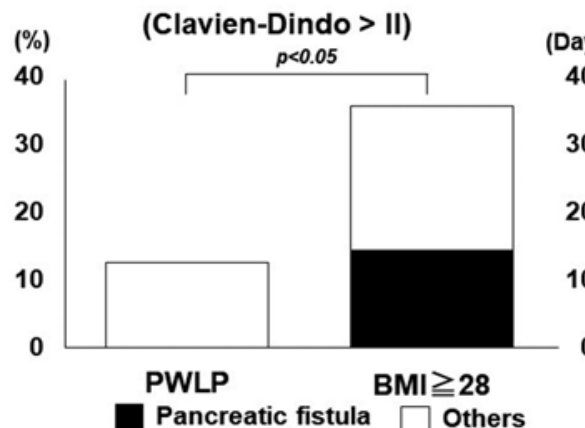

\section{b. Blood loss}

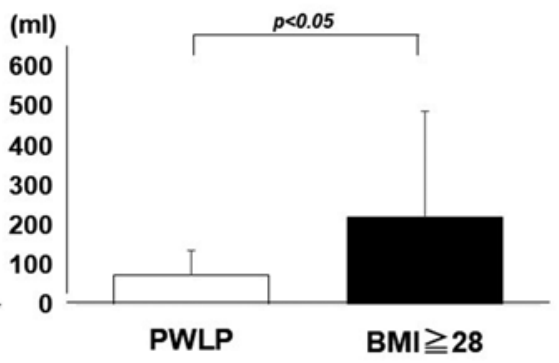

\section{d. Postoperative hospital stay}

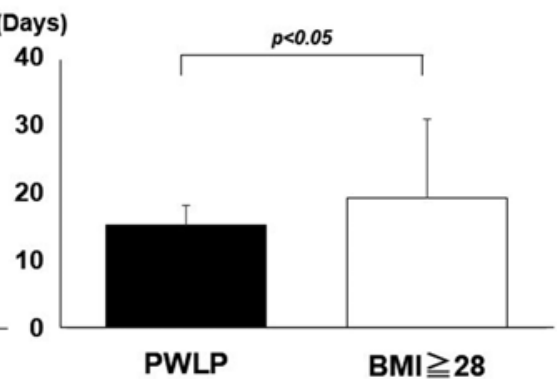

Figures $4 \mathrm{a}-4 \mathrm{~d}$. Comparisons of operation times (4a), blood loss (4b), post-operative complications (4c) and post-operative hospital stays (4d) in the PWLP and BMI $\geqq 28$ groups.

The unpaired Student's t-test was used for the statistical analysis of the continuous variables. $\mathrm{P}<0.05$ was interpreted as significant. The values for each continuous variable are expressed as a mean \pm the standard deviation (SD). 
including pancreatic fistula.

For the purpose of improving the operative outcomes, a PWLP was started in the Department of Surgery, Tokushima University with the approval of a suitably constituted Ethics Committee of Tokushima University Hospital.

Regarding bariatric surgery, a pre-operative diet with immune-nutrition formulas achieved a pre-operative weight loss, lower post-operative pain and lower CRP and liver enzymes in laparoscopic sleeve gastrectomy than high-protein formulas or regular diet, all of them with similar caloric intake (9).

However, one of the important problems in weight loss is the incidence of sarcopenia. Decrease of skeletal muscle, referred to as sarcopenia, was reported to correlate with the morbidity and mortality in the patients undergoing digestive surgery. 'Unintentional' weight loss could be used to predict mortality and morbidity rates in colo-rectal surgery. Pre-operative weight loss had a significant association with cardiopulmonary complications (10). Kaido. et al. reported that sarcopenia was closely related with post-operative mortality in the patients undergoing LDLT and peri-operative nutritional intervention was important for the survival of patients with sarcopenia (11). 'Sarcopenic obesity' was defined as the criteria for sarcopenia and obesity by body fat mass (male $\geqq 25 \%$, female $\geqq 35 \%$ ). Regarding HCC, pre-operative sarcopenic obesity was an independent risk factor for the survival of the patient and recurrence of the condition after operation (12).

In pre-operative weight loss, the prevention of sarcopenia is very important for the decrease of peri-operative complications. In this study, the PWLP showed no decrease of skeletal muscle with the maintenance of several nutritional factors.

The progression of GC during the PWLP is one of the important problems. H.J.F. Brenkman, et al. reported that a longer waiting time (even if $>8$ weeks) until the start of the gastrectomy surgery for GC was not associated with a worse overall survival (13). So, the duration of the PWLP for $19-40$ days might be reasonable for the purpose of decreasing post-operative complications.

In conclusion, obesity is an important risk factor and a PWLP is useful for obese patients undergoing LG surgery.

\section{ACKNOWLEDGEMENTS}

The authors are grateful to the staff at the Department of Surgery, Institute of Health Biosciences, Tokushima University, for their important contributions.

Hideya Kashihara and the other co-authors have no conflict of interest.

All investigations on human subjects must include a statement that the subject gave informed consent and patient anonymity should be preserved.

\section{REFERENCES}

1. Kitano S, Iso Y, Moriyama M, Sugimachi K: Laparoscopy assisted Billroth I gastrectomy. Surg Laparosc Endosc $4: 146-8,1994$

2. Adachi Y, Suematsu T, Shiraishi N, Katsuta T, Morimoto A, Kitano S, Akazawa K: Quality of life after laparoscopy assisted Billroth I gastrectomy. Ann Surg 229 : 49-54, 1999

3. Memon MA, Khan S, Yunus RM, Barr R, Memon B: Meta-analysis of laparoscopic and open distal gastrectomy for gastric carcinoma. Surg Endosc 22 : 1781-9, 2008

4. Kunisaki C, Makino H, Takagawa R, Sato K, Kawamata M, Kanazawa A, Yamamoto N, Nagano Y, Fujii S, Ono H, Akiyama H, Shimada $\mathrm{H}$ : Predictive factors for surgical complications of laparoscopy-assisted distal gastrectomy for gastric cancer. Surg Endosc 23(9) : 2085-93, 2009

5. Jiang X, Hiki N, Nunobe S, Kumagai K, Nohara K, Sano T, Yamaguchi T: Postoperative pancreatic fistula and the risk factors of laparoscopy-assisted distal gastrectomy for early gastric cancer. Ann Surg Oncol 19(1) : 115-21, 2012

6. Japanese Gastric Cancer Association : Japanese gastric cancer treatment guidelines 2014 (ver. 4). Gastric Cancer 20(1) : 1-19, 2017

7. Yoshikawa K, Shimada M, Kurita N, Iwata T, Nishioka M, Morimoto S, Miyatani T, Komatsu M, Mikami C, Kashihara $\mathrm{H}$ : Visceral fat area is superior to body mass index as a predictive factor for risk with laparoscopy-assisted gastrectomy for gastric cancer. Surg Endosc 25(12) : 3825-30, 2011

8. Goto H, Kanaji S, Yasuda T, Oshikiri T, Yamamoto M, Matsuda T, Nakamura T, Suzuki S, Fujino Y, Tominaga M, Kakeji Y: The Depth from the Skin to the Celiac Artery Measured Using Computed Tomography is a Simple Predictive Index for Longer Operation Time During Laparoscopic Distal Gastrectomy. World J Surg 42(4) : 1065-1072, 2018

9. Ruiz-Tovar J, Zubiaga L, Diez M, Murcia A, Boix E, Muñoz JL, Llavero C, OBELCHE group : Preoperative Regular Diet of $900 \mathrm{kcal} /$ day vs Balanced Energy High-Protein Formula vs Immunonutrition Formula : Effect on Preoperative Weight Loss and Postoperative Pain, Complications and Analytical Acute Phase Reactants After Laparoscopic Sleeve Gastrectomy. Obes Surg 26(6) : 1221-7, 2016

10. Moghadamyeghaneh Z, Hanna MH, Hwang G, Carmichael JC, Mills SD, Pigazzi A, Stamos MJ : Outcome of preoperative weight loss in colorectal surgery. Am J Surg 210(2) : 291-7, 2015

11. Kaido T, Ogawa K, Fujimoto Y, Ogura Y, Hata K, Ito T, Tomiyama K, Yagi S, Mori S, Uemoto S : Impact of sarcopenia on survival in patients undergoing living donor liver transplantation. Am J Transplant 13(6) : 1549-56, 2013

12. Kobayashi A, Kaido T, Hamaguchi Y, Okumura S, Shirai H, Yao S, Kamo N, Yagi S, Taura K, Okajima H, Uemoto $\mathrm{S}$ : Impact of Sarcopenic Obesity on Outcomes in Patients Undergoing Hepatectomy for Hepatocellular Carcinoma. Ann Surg 269(5) : 924-931, 2019

13. Brenkman HJF, Visser E, van Rossum PSN, S Siesling, van Hillegersberg R, Ruurda JP : Association Between Waiting Time from Diagnosis to Treatment and Survival in Patients with Curable Gastric Cancer : A Population-Based Study in the Netherlands. Ann Surg Oncol 24(7) : 1761-1769, 2017 